\title{
Policy change in nascent subsystems: Mozambican higher education policy 1993-2003
}

\author{
Jasmin Beverwijk · Leo Goedegebuure · Jeroen Huisman
}

Published online: 30 November 2008

(C) The Author(s) 2008. This article is published with open access at Springerlink.com

\begin{abstract}
The Advocacy Coalition Framework (ACF), developed by Sabatier and Jenkins-Smith in the late 1980s, has proven to be a valuable theory to explain policy change. At the same time, however, researchers have identified limitations in the ACF relating to various dimensions such as definitions of key variables, their operationalization, and the universal applicability of the framework to any context, be it Europe, the US, or countries outside the OECD. The key question addressed in this article is whether the ACF, like most other established public policy theories or frameworks developed in a western industrialized context, can be applied to very young (sub)systems in volatile contexts. We try to answer this question by applying the ACF to the development of the Mozambican higher education subsystem, a subsystem that fits the conditions of volatility and nascence. On the one hand this subsystem is characterized by a turbulent environment and a weak democracy. On the other hand, the higher education subsystem is built practically from scratch. The findings of the study suggest that the ACF is built on basic assumptions that do not apply to a country with a high degree of civil and political turbulence. Some revisions need to be made to improve the ACF's fit to such a context.
\end{abstract}

Keywords Advocation Coalition Framework - Policy change - Nascent subsystems · Higher education · Mozambique

\footnotetext{
J. Beverwijk $(\square)$

CHEPS (Center for Higher education Policy Studies), University of Twente, P.O. Box 217, 7500 AE Enschede, The Netherlands

e-mail: j.m.r.beverwijk@utwente.nl

L. Goedegebuure

School of Professional Development and Administrative Leadership, University of New England, Armidale, NSW 2351, Australia

J. Huisman

International Centre for Higher Education Management, School of Management, University of Bath, Bath BA2 7AY, United Kingdom
} 


\section{Introduction}

Over the past 15 years a substantial body of literature has emerged on the applicability of the Advocacy Coalition Framework (ACF) developed by Sabatier and Jenkins-Smith to different regions in the world and to various policy domains. The framework has proven to be valuable to explain policy processes and change (e.g., Fenger and Klok 2001; Parsons 1995; Eberg 1997; Schlager and Blomquist 1996; Grin and Hoppe 1997). It argues that, acting on the basis of beliefs, actors form coalitions and press to have their beliefs realised in public policy. According to Sabatier and Jenkins-Smith (1999), the ACF is a young theoretical framework still under development. On the basis of empirical applications and critique by others, Sabatier and Jenkins-Smith have adapted the ACF. They have made changes to the theoretical framework, revised some of the hypotheses, and added several new ones (for an assessment and overview of these changes, see Sabatier and Jenkins-Smith 1999; Sabatier and Weible 2007). In addition, they point out that more empirical research is needed that systematically relates the core variables of the ACF to actual policy changes. Moreover, they argue that the majority of the studies apply the ACF to industrialized regions, with only a couple of studies being applied to countries outside the OECD (see, for instance, Anderson 1999; Elliot 1999). These appear to indicate that the applicability of the ACF is not limited to OECD countries. However, Sabatier and Jenkins-Smith (1999) point out that more research needs to be done to come to a full assessment of the ACF in non-industrialized countries.

In order to gain more insights into the applicability of the ACF in developing countries, this study analyzed policy developments in Mozambican higher education over a 10-year period. These policy and change processes took place, as we will argue, in (1) unstable and turbulent contexts, and (2) in a nascent subsystem.

The remainder of this article is divided into six sections. Section "The Advocacy coalition framework" provides an overview of the theoretical model underlying the research and details the key concepts of the study. In the section "Expectations", the basic expectations are developed. Section "Methodology and operationalization of variables" operationalizes the key variables for this study and addresses the methodology used. Section "Coalition behavior and policy in Mozambican higher education" analyzes the Mozambican higher education policy changes in light of the expectations formulated, which are tested in section "Testing the hypotheses". The last section contains the conclusions that can be drawn on the basis of this study.

\section{The Advocacy coalition framework}

The Mozambican case study focuses on three particular aspects of the ACF: (1) beliefs in nascent subsystems, (2) major policy change in unstable and turbulent contexts, and (3) the role of beliefs and resources in common action and policy change. To study these aspects, the key variables-(nascent) subsystem, advocacy coalition, beliefs, resources, common action, and external factors-are conceptualized. Subsequently three expectations are formulated.

Subsystems and nascent subsystems

A subsystem refers to the interaction of advocacy coalitions from different institutions who seek to influence governmental decisions in a specific policy area (Sabatier and 
Jenkins-Smith 1993, p. 16). Sabatier and Jenkins-Smith assume that every subsystem contains a large number of actors. It does not only consist of one governmental institution but of actors from a variety of public and private organizations actively concerned with a policy issue or problem, be it air pollution control, mental health or-as in this article- the development of a higher education sector.

In later work Sabatier and Jenkins-Smith made a distinction between mature and nascent subsystems in order to indicate the extent of coalition stability (Sabatier and Brasher 1993). They posit that mature subsystems exist for a long time with actors having clear and stable positions. In contrast, nascent subsystems regularly emerge in situations where actors have become dissatisfied with the existing subsystem neglecting a particular aspect of a policy problem, and they therefore form their own, new subsystem. A second reason for subsystems to arise is when policy issues are reconceptualized or perceived differently due to new external developments. Sabatier and Jenkins-Smith point out that it is important to distinguish between these different conditions under which new subsystems may emerge, because this affects the nature of coalitions and coalition formation in the nascent subsystem (Sabatier and Jenkins-Smith 1999, p. 136). In the first situation, the new subsystem is a spin-off of existing ones. Sabatier and Jenkins-Smith expect clearly differentiated coalitions (mirroring pre-existing groups) to emerge. In the second situation, they expect an amorphous situation where policy beliefs are fragmented and coalitions are unstable (ibid., p. 137).

\section{Advocacy coalition}

The heart of the ACF is an advocacy coalition, which the authors define as comprising people from a variety of positions (elected and agency officials, interest group leaders, researchers, etc.) who share a particular belief system - that is, a set of basic values, causal assumptions, and problem perceptions - and show a nontrivial degree of coordinated activity over time (Sabatier and Jenkins-Smith 1993, p. 25). In their attempts to successfully reach their policy goals, members of an advocacy coalition coordinate their activities and develop strategies over time that seek to make governmental institutions behave in accordance with their policy beliefs (Sabatier and Jenkins-Smith 1999, p. 142).

Subsystems generally consist of a dominant advocacy coalition and one or more minority advocacy coalitions where the former is in the position to determine policy processes. Each coalition will seek to realise its policy objectives over time. The minority coalitions can seek to improve their relative position through augmenting their resources, though their basic chance of gaining power within a subsystem resides in waiting for external events such as elections (Sabatier and Jenkins-Smith 1993, p. 35).

\section{Beliefs and policy change}

A belief system refers to the set of basic beliefs that actors in an advocacy coalition hold. The ACF distinguishes between three belief system levels: (1) deep core, (2) policy core, and (3) secondary aspects. The deep core refers to the individual's underlying personal philosophy and includes basic ontological and normative assumptions about human nature and the priority of fundamental values such as liberty or equity. This belief usually applies to all policy fields and provides the foundation for other, more specific beliefs (Sabatier and Jenkins-Smith 1999, p. 121). The policy core relates to a specific policy field or subsystem. It includes the basic strategies and policy positions for achieving deep core beliefs in the policy area of a subsystem and involves topics such as whose welfare counts, 
the relative authority of governments versus the market, and the role of various actors in the policy subsystem. Secondary aspects are narrow in scope and relate to particular aspects of the policy area. They refer for instance to beliefs concerning the seriousness of the problem or the relative importance of various causal factors (Sabatier and JenkinsSmith 1999, p. 121).

According to Sabatier, public policies (or programmes) can be conceptualized in the same manner as belief systems (Sabatier 1988, p. 131). This would imply that if policy beliefs change, policies will change too. Some aspects of the belief system, and therefore also the public policy, change far more frequently that others. Within the hierarchy of layers, the secondary aspects are assumed to change more frequently than the policy core, which in turn changes more frequently than the deep core aspects. Changes in the policy core are usually the result of perturbations in non-cognitive factors external to the subsystem, such as elections or changes in the socio-economic conditions, or because of outputs from other subsystems. The ACF assumes that these types of external factors are relatively stable and rarely, or only after a long time, change. Consequently, core beliefs that are affected by these external factors change slowly, generally after a decade or more (Sabatier and Jenkins-Smith 1993). Changes to the deep core seldom happen. Sabatier and Jenkins-Smith do not elaborate further on this issue in their work.

\section{Resources/common action}

In the $\mathrm{ACF}$, the notion of resources is closely related to the notion of common action: resources enable actors to take common actions. Coalition resources include money, coalition members and supporters, expertise and legal authority (Sabatier and JenkinsSmith 1993, p. 29). The (re)distribution of resources among subsystem actors is generally determined by factors outside the policy subsystem.

Common action (or coalition behavior) between subsystem actors is carried out through the different strategies advocacy coalitions use. Especially in the early stage of the ACF, the concept of resources was poorly developed. Fenger and Klok (2001), building on Zafonte and Sabatier's (1998) work, contributed to the ACF by exploring how resource factors determine the extent and nature of interdependency between actors and influence interaction between actors seeking to advance policy changes. According to Fenger and Klok, the concept of interdependency relates to the role that resources play in enabling actors to take actions (Fenger and Klok 2001, p. 162). They specify three types of interdependency: symbiotic, independent, and competitive, together with three types of beliefs: congruent, indifferent, and divergent (see Table 1). The situation where the action of one actor interferes with another actor's ability to take action is labelled as competitive interdependency. Symbiotic interdependency refers to the situation where one actor's actions contribute to another actor's actions or goal achievement. When actors are independent, they do not need the same resources in order to perform (Fenger and Klok 2001, p. 162).

In the upper left cell of Table 1 (congruent beliefs and symbiotic interdependency) actors are expected to be in the same coalition and will not face great difficulties in coordinating their activities since all actors are better off in the end. The middle left cell indicates that if beliefs are congruent and interdependency is independent, beliefs will bring actors together. However, if interdependency is competitive (bottom left cell), it will have a seriously destabilising impact on the coalition. In line with the ACF's basic assumption, beliefs are seen as the principal glue of coalitions. It is therefore expected that actors will form a coalition along the lines of their beliefs, but will struggle to maintain it. 
Table 1 Coalition behavior as the result of interdependency and belief congruence

\begin{tabular}{llll}
\hline Interdependency & Policy core beliefs & & \\
\cline { 2 - 4 } & Congruent & Indifferent & Divergent \\
\hline Symbiotic & Strong co-ordination & Coalitions of convenience & $\begin{array}{c}\text { Unstable conflict, } \\
\text { depolarisation } \\
\text { learning }\end{array}$ \\
Independent & Weak co-ordination & No coalition & Weak conflict \\
Competitive & Collective action & Weak conflict & Strong conflict \\
& with severe problems & & \\
\hline
\end{tabular}

Source: Fenger and Klok 2001

The coalition is expected to be unstable due to the diverging forces of competitive interdependency. If beliefs are divergent and interdependency is symbiotic (upper right cell), the result is more difficult to explain. On the basis of assumptions indicated by the AFC, one would expect actors to be members of conflicting coalitions. However, because they are-at the same time-dependent on each other, both conflict and learning opportunities arise (Fenger and Klok 2001, p. 8).

\section{External factors}

External factors include (1) relatively stable parameters, and (2) dynamic events and resources. Dynamic events external to the subsystem can be divided into three main categories: (1) changes in socio-economic conditions, (2) changes in governing coalitions, and (3) outputs from other subsystems that provide opportunities or obstacles to the competing coalitions. The stable parameters are divided into four main categories: (1) basic attributes of the problem area (or good), (2) basic distribution of natural resources, (3) fundamental socio-cultural values, and (4) social structures (Sabatier and Jenkins-Smith 1993, p. 21).

\section{Expectations}

Having discussed the focus of this study and conceptualized the key variables, the following section turns to the expectations that we believe can be derived from this.

Expectation regarding beliefs in nascent subsystems

Because the Mozambican higher education subsystem only emerged in the $1990 \mathrm{~s}^{1}$ it is considered a nascent subsystem. Sabatier and Jenkins-Smith distinguish two types of nascent subsystems, namely: (1) those that arise where actors have become dissatisfied with the existing subsystem because it neglects a particular aspect of a policy problem and they therefore form their own subsystem, or (2) those that arise when policy issues are reconceptualized or perceived differently due to new external developments.

\footnotetext{
${ }^{1}$ In Mozambique the higher education system emerged during turbulent times. It is of no use analyzing the system in general before the early 1990s as up to that point all policies, including that of higher education, solely reflected the government's desires. The perceptions and beliefs of other actors were neglected. An open debate about policy beliefs is a key element in the ACF, which was not possible until the early 1990s.
} 
The Mozambican higher education subsystem is clearly a case of a subsystem that arises out of new issues or a new conceptualization. The subsystem's origins have consequences for actors' beliefs and coalitions. In this case, the actors' policy core beliefs are expected to be fragmented (Sabatier and Jenkins-Smith 1999, p. 137). Sabatier and Brashers' (1993) study of environmental policy at Lake Tahoe shows that fragmentation of beliefs can be regarded as a phenomenon whereby (1) policy cores are vaguely formulated, (2) actors espouse different policy cores, and (3) actors' policy core beliefs change rapidly. Hence actors change coalitions in relatively short periods. Therefore:

Expectation 1 In nascent subsystems that emerge out of new issues or a new conceptualization, policy core beliefs are fragmented.

Expectation regarding interaction between subsystem actors

According to the ACF, policy change is affected by the interaction of subsystem actors. On the basis of Fenger and Klok's (2001) contribution it is assumed that the type of resources and the type of policy core beliefs that the subsystem actors possess will determine whether actors join an advocacy coalition to realize common goals and subsequently determine the type of effort needed to realize those common goals. This study tests if these expectations apply to Mozambican higher education policy development.

Expectation 2 The type of interaction between actors is dependent on the interaction between the nature of the policy beliefs that actors hold and the nature of the interdependency of actors.

Expectation regarding major policy changes

Due to "shocks" from outside the subsystem, policy core beliefs within the advocacy coalition can be reviewed and adapted, resulting in major policy changes. For a redistribution of political power between dominant and minority advocacy coalitions to occur, there is a need for significant perturbations external to the subsystem, such as shifts in governments. In the latter case, a change in the external environment is necessary, but not sufficient to cause change in the policy core attributes. The perturbations provide an opportunity for major policy change, but that change will not occur unless proponents of change, that is, the minority coalition, skilfully exploit that opportunity (Sabatier and Jenkins-Smith 1999, p. 148). Thus:

Expectation 3a Major policy change (referring to change in the policy core aspects of a governmental programme) happens infrequently, that is, only after a decade or more.

Expectation $3 \mathrm{~b}$ If major policy change occurs, it is due to changes external to the subsystem.

\section{Methodology and operationalization of variables}

\section{Methodology}

The following section sets out the methodology and type of data collection used for this study and the operationalization of variables. In order to study the developments in Mozambican higher education policy from 1993 to 2003 a case study approach was used. This included the collection of different types of data and a variety of research techniques: 
participant observation, interviews, and analysis of written information/documents. The bulk of the fieldwork was carried out between August 2000 and July 2003. Policy developments from 1993 to 1999 were reconstructed on the basis of written sources and interviews with people active in the higher education policy subsystem during that period. Beyond the obvious key actors, we asked those who played a role in the period 2000-2003 to mention names of persons they thought were past key players. Policy developments from 2000 to 2003 were observed closely as they unfolded and analyzed through (participant) observation and structured and semi-structured interviews. We realise that not being able to do participatory observation over the period 1993-2000 was a disadvantage, as this would have delivered appropriate and robust information. However, we do believe that we did obtain an adequate and reliable picture of actors' beliefs and the outcome of key events that had taken place because we were able to talk a number of times to the key actors who played a role in the higher education subsystem between 1993 and 2000. The relatively small size of the subsystem made it possible to speak with almost all important actors. In 1993 the sector consisted of three public higher education institutions, and in 2000 it consisted of four public higher education institutions and five private higher education institutions. Since the rectors of the public universities had autonomy and were directly appointed by the State President, they had the status of a minister and therefore other ministries, such as the Ministry of Education and the Ministry of Finance and Planning, hardly interfered with these institutions. At that stage, the business sector and donors' role was limited. With regards to the analysis of written documents, only a small number of key documents focusing on higher education policy were produced in this period and all were well archived. We therefore are sure we analyzed all documents relevant for an understanding of the development of the higher education subsystem. Our subsequent interviews support this claim.

To get a clear overview of people's contribution to the higher education policy developments, we selected key people whom we interviewed multiple times over a period of three years. In this way we could see whether and how perceptions of key actors in the higher education subsystem had changed between 2000 and 2003. The basic criterion to select actors was that they must have been active in contributing to the development of higher education policies. Almost one hundred structured and semi-structured interviews were conducted with key actors. These included: rectors and vice-rectors of all higher education institutions in Mozambique, the Minister of Higher Education, Science and Technology, advisors to the Minister, heads of department in the Ministry of Higher Education, Science and Technology (MESCT), members of parliament dealing with higher education, key people in the Ministry of Education (MINED) and Ministry of Planning and Finance (MPF), including the former Minister of Education and the Deputy Minister of Education, the major donor organizations that financially contributed to the higher education sector, and directors of four major private business organizations located in Mozambique.

Written information was studied for two purposes. First of all we were interested to see to what extent verbal information and written information coincided. If the two sources of information differed we tried to find out why there were different perceptions on certain developments and who exactly had different opinions. Secondly, written information gave insights into past events and developments, and into the history of MINED and MESCT. MESCT allowed us to study archival documents such as policy proposals, policy papers, minutes of meetings, letters, newsletters, and annual reports. Information was also obtained from higher education institutions, donor organizations and newspapers.

With respect to the observations, a variety of both formal and informal events were attended, ranging from official meetings to dinner parties. The discussions at these events 
provided much information as they revealed relevant policy issues at that time. They exposed what types of policy decisions were considered, actors' concerns, which issues were sensitive, and the conflicts and topics on which subsystem actors agreed. Moreover, it was useful to participate in these events as the discussions clarified who believed what and how the actors reacted to policy proposals. The different perceptions were used at a later stage in the interviews to generate further discussion with these actors.

MESCT gave permission to observe most activities in the different departments in the Ministry. Access was granted to meetings, both internal and with people from outside MESCT such as donors, people from higher education institutions or the business sector. In addition we were invited to attend seminars, workshops and national conferences. During this period office space at MESCT was provided. MESCT staff always kept their "roommates" informed about the latest developments through discussions (subjects, outcomes, their (dis)satisfaction, concerns, and surprises) after every meeting, seminar or specific document they read or had to prepare. By participating in these discussions and asking further specific questions on the perceptions of the different actors who had attended the meetings, it was possible to also obtain insights into events which we could not attend. Thus, working regularly in the offices shared with MESCT staff kept us abreast of the latest developments. We realized that such close proximity might induce bias towards subsystem actors other than those working for MESCT. We therefore arranged formal and informal visits or meetings with people from higher education institutions, donor organizations and the business sector to balance the picture of their work and how they related to the higher education policy issues.

\section{Operationalization}

The key variables underpinning the analysis, namely beliefs, resources and common action, were operationalized in the following ways.

\section{Beliefs}

Sabatier and Jenkins-Smith indicate that scope of system and topic should be the defining characteristics of policy core beliefs and that it is this belief that is most strongly related to indicators of coordinated behavior. With respect to scope, deep core beliefs relate to issues at system level, policy core beliefs relate to issues at subsystem level, and secondary aspects relate to certain elements of the subsystem. Topic means that it should pertain to one the subjects listed under "policy core" (Sabatier and Jenkins-Smith 1999, p. 132). Sabatier and Jenkins-Smith developed a list of policy core topics (e.g., the topics "overall seriousness of the problem", "basic causes of the problem", and "distribution of authority between actors"). For our study, this list was used as the guiding principle to distinguish between the three layers in the belief system.

\section{Resources}

Sabatier and Jenkins-Smith (1993) argue that coalition resources include aspects such as money (financial resources) and members (authority). We added the resource "information" since in the ACF perspective policy development generally happens after consultation with subsystem actors and monitoring of activities, based on data supplied by actors in the policy subsystem. The three items were operationalized as follows. 
With respect to financial resources this study traced who controlled funding and how funding mechanisms for higher education institutions were regulated and changed. To obtain insights the study analyzed which actors provided funds to higher education institutions and whether there was a change in the amount and type of funding or the requirements to access it. This information outlined the dependency relations between subsystems actors. To operationalize authority the study focused on the formal decisionmaking power of subsystem actors: which subsystem actors had decision-making power in what areas and which changes took place over the years? The study analyzed whether new actors could obtain decision-making power in certain areas, and whether established actors lost power or had to share power. In order to operationalize the variable "information", the study focused on information streams between subsystem actors concerning higher education policies. It unravelled who provided whom with what type of information and for what purpose, and how subsystem actors reacted to the information.

\section{Interaction}

This study follows Fenger and Klok's (2001) nine types of coalition behavior (Table 1). Given that "weak conflict" is an outcome of coordination that occurs twice under different circumstances and that one outcome refers to the situation where no interaction occurs at all, in practice only seven different types of interaction are distinguished.

First, a distinction is made between coordination and conflict. Coordination refers to the spectrum of activities in which one coalition alters its political strategy to accommodate the activity of others in pursuit of similar goals (Zafonte and Sabatier 1998). By contrast, conflict refers to the spectrum of activities in which the political strategies of one party are aimed at preventing other parties from pursuing divergent goals (Fenger and Klok 2001). Both forms of interaction have a weak and a strong form; which form arises depends on the types of strategies coalitions use. For weak coordination and weak conflict soft strategies are used, such as negotiation, whereas for strong coordination and strong conflict coalitions use more rigorous strategies like going to court. The operationalization of the following types of coordination and conflict is based on Fenger and Klok's work (2001).

\section{Strong coordination}

Strong coordination requires: (1) development of a common plan of action, (2) communication of that plan to potential coalition members, (3) monitoring of member compliance, and (4) imposition of sanctions for non-compliance. Strong coordination is likely to last for a long period of time.

\section{Weak coordination}

Weak coordination does not require the rigorous strategies mentioned above. Instead it simply requires the potential members of a coalition to (1) monitor each other's behavior, and (2) alter their own behavior to make it complementary.

\section{Strong conflict}

Strong conflict points to situations in which coalitions develop more rigorous strategies to prevent other parties from pursuing their goals. Coalitions use strategies that aim to make life as difficult as possible for other coalitions with divergent beliefs. 
Weak conflict

As with weak coordination, weak conflict occurs when organizational actors monitor each other's political behavior and then alter their actions to prevent the pursuit of goals by the other party.

Coordination based on unstable conflict

Coordination based on unstable conflict occurs when (1) coalitions use soft strategies and search for a compromise, and (2) actors are symbiotically dependent on each other and have divergent beliefs.

This type of coalition behavior relates closely to weak conflict. Yet because the actors are symbiotically dependent on each other, Fenger and Klok classify this type of interaction as coordination based on unstable conflict. One way of coping with this would be through a strategy of depoliticisation, where actors stick to their divergent beliefs but develop a general compromise that enables them to work together with actors from the other coalition. An example of this would be through formulating common goals broadly and vaguely.

Severe collective action problems

Severe collective action problems occur when (1) coalitions initially engage in common action (weak or strong) but fall apart once actors discern that the coalition's ability to influence policy does not successfully lead to common policy goals, and (2) actors hold congruent core beliefs but compete for the same resources.

Common beliefs bring actors together, but competitive interdependency drives them apart and therefore they will be confronted with severe collective action problems: coalition behavior will therefore be unstable. That is, once actors notice that the strategies developed to realise a common goal are not successful, the coalition will fall apart.

Coordination of convenience

Coordination of convenience occurs when actors (1) seek to align their activities, and (2) have neither conflicting ideas nor congruent perceptions and beliefs, whilst being symbiotically dependent on each other in terms of resources. This type of coalition behavior is similar to weak coordination, but due to the different conditions under which it occursindifferent beliefs and symbiotic interdependence-it implies that there will be a loose form of cooperation between coalition actors. This coalition is primarily based on shared interests, not on shared beliefs.

\section{Coalition behavior and policy in Mozambican higher education}

This section analyzes the origins of the Mozambican higher education subsystem and looks at the interaction between actors who seek to influence higher education policy and at the nature, cause and frequency of policy changes. On the basis of our empirical analyses three periods of policy change can be identified: 1993-1999, 2000-2002, and 2003. 
Policy developments 1993-1999

Since the 1990s, after almost 30 years of devastating war, the higher education sector in Mozambique has been practically reinstitutionalized. The first "higher education subsystem" (1962-1974) consisted of one national university based on colonial ideologies. In practice this meant that higher education was reserved for the rich Portuguese. After the Portuguese left, the Government of Mozambique adopted a Marxist-Leninist ideology. From 1974 to the beginning of the 1990s, Mozambique had three universities, which were centrally planned and governed according to clear party and government prescriptions with respect to curriculum, staff, students and the entire infrastructure (Mário et al. 2003). By the end of the 1980s, the government abandoned the strict socialist programme and moved towards a more liberal constitution which included democracy and free market principles. During these years the higher education subsystem was small; it consisted of only three rectors, government representatives from the Ministry of Education (MINED) and the Ministry of Planning and Finance (MPF), and provincial governors.

During the early 1990s, both the rectors and the Government of Mozambique were concerned about higher education and believed it needed more attention and reform. Their concern can be derived from the enactment of Law no. 1/93 on higher education. The law defined the autonomy of existing higher education institutions, decreasing the government's influence in the sector, and established the National Council for Higher Education (CNES). This Council consists of the rectors of all institutions (public and private) and advises the Cabinet on higher education (Boletim de República, Law no. 1/93, 1993). In reaction to the growing demand for higher education and an insufficient capacity in the public institutions, Law no. 1/93 authorized the establishment of private higher education institutions. During the first 3 years, from 1993 to 1996, little happened in the higher education subsystem. There are no indications in the formal documents of activities or discussions around higher education policy. This has been corroborated in our semi-structured interviews held with people from MINED and the MPF who were in charge of higher education, with rectors of higher education institutions, members of parliament and donors. From 1996 onwards, actors in the higher education subsystem became more active in addressing perceived problems (Brito 2003). Rectors, members of parliament and government officials at the provincial and national level lobbied for a national coordinating unit to guide policy development. They believed the increasing demand for higher education and the sudden expansion of (private) institutions required active guidance and support from government as the subsystem drifted towards a sector consisting of inefficient institutions not able to meet the demands and needs of society. The actors engaged in common action by undertaking studies and organizing seminars in order to influence the government.

During this period one policy core belief supported by all actors could be identified, namely the need for a sector-wide higher education policy to overcome the identified problems and meet the needs of society. In their effort to operationalize 'policy core' Sabatier and Jenkins-Smith point out that "distribution of authority amongst actors" is a typical policy core topic (Sabatier and Jenkins-Smith 1999, p. 133). Moreover, this distribution of authority amongst actors affects the whole higher education subsystem which is an important criterion for policy core issues. We therefore classify perceptions on "new coordination mechanisms" as a policy core issue. It was thus one coalition, which we labelled the systemic coalition, which sought to convince the government of the need for this national coordination unit.

The coalition's action and strategies to push the government into creating a new national coordination unit responsible for the sector can be characterised as weak 
coordination. The actions did not require any elaborate decision-making or monitoring processes. Generally, all actors supported the need for a new ministry in charge of higher education, science and technology.

In terms of resources, until 1999 the higher education institutions that were part of the systemic coalition acted to a large extent independently from the government. Rectors from public universities directly negotiated with the MPF concerning the funding of future plans without interference from MINED. Funding was not based on performance, but was defined by the actual level of expenditures per category in the preceding budget period. It covered staff costs, educational inputs and non-educational expenditure (staff housing, student bursaries, food, etc.). Legally, higher education institutions fell under MINED, yet in practice its role was limited (Boletim de República, Law no. 1/93, 1993). Each university developed its own policy on aspects such as quality assurance and access requirements. The exchange of institutional data or information between institutions and MINED was limited, given that there was little national higher education policy development.

Due to the actors' strategies, the newly elected Government of Mozambique decided in 2000 to put higher education at the top of the agenda and establish the Ministry for Higher Education, Science and Technology (MESCT). It was given the task to develop a higher education sector-wide policy to overcome the problems identified in higher education (Boletim de República, Law no. 14/2000, 2000). This policy change can be classified as a major one, because it coincided with the policy core topic "(re)distribution of authority". At the end of 2000, the higher education subsystem consisted of one coalition with actors being independent from each other and engaged in weak coordination to realise their common policy goal.

Policy developments from 2000 to 2002

MESCT was a new organization and therefore had to be built from scratch, which meant that staff had to be recruited to conduct work in the Ministry. From 2000 to 2002, the Ministry consisted of the Minister and three policy advisors and support staff such as secretaries. The Ministry was furthermore supported by a small number of administrators and temporary committees that operated for about half a year on a certain policy issue. These committees generally consisted of critical and ambitious academics from universities who were interested to be part of the process to reform the higher education sector as they were experiencing the obstacles and difficulties in the sector every day. The new staff in MESCT and people from the committees had different backgrounds, for example former politicians, academics, people that had been working in the Ministry of Education, and lawyers. All were recruited and appointed directly by the Minister. Certainly, in this way the Minister was able to ensure that all staff were aligned with the policy beliefs she had about future directions of the higher education sector.

During the period 2000-2002 the actors sought to give meaning to the sector-wide policy development. MESCT played a key role in this process as it initiated policies. On the basis of its perception of what a Mozambican higher education sector should entail, the new Ministry developed and proposed various new policies and regulations. One of MESCT's initiatives was the proposal for a new law on higher education, science and technology. This proposal was complemented by the development of new policies such as a funding policy, a new advisory body to the Council of Ministers on higher education, science and technology, the establishment of a quality assurance and credit transfer system, the establishment of new institutions that offered different degrees, and the development of new degree structures (MESCT, 2000). 
Although it can be argued that these proposals did indeed reflect the concept of a higher education sector-wide policy to deal with the problems, for the rectors it was also more than they had bargained for. Fearing a loss of their substantive autonomy, they opposed a number of the MESCT initiatives, such as the quality assurance system, the degree structure, and the composition of the new advisory body. Though argued differently, all of this boiled down to one general policy core: the division of power and authority in the system. The rectors perceived MESCT to gain too much power at their own expense; a perception that can be understood given that MESCT believed it should have a decisive role in policy development and planning in the higher education sector. In addition, it wanted to balance the consultative powers between rectors and other actors representing key organizations in society relevant to higher education. However, MESCT also forcefully argued that it had no intention of imposing rules or taking over the management of the institutions. According to the Minister, the crux was that the rectors misunderstood the notion of autonomy (Brito 2003).

The proposal to introduce "new co-ordination mechanisms" is closely linked to the concept of "distribution of authority amongst actors". On the basis of interviews with all subsystem actors, we concluded that there were two advocacy coalitions holding different perceptions on the policy core belief "distribution of authority among actors". In broad terms, MESCT, donors, the business sector, representatives from MINED and the MPF, and members of parliament advocated sector-wide decision making and planning (systemic coalition), whereas the rectors advocated more institutional autonomy (autonomy coalition). Thus, during the period 2000-2002 a second coalition emerged in the higher education subsystem. From 1993 to 1999, the rectors were part of the systemic coalition to push for the establishment of a government unit in charge of developing a system-wide policy. Once MESCT was established, between 2000 and 2002 the rectors separated from the systemic coalition and regrouped in the autonomy coalition where they sought to push for more institutional decision-making power and autonomy.

Organized opposition appeared during the formation of Law no. 05/2003 on higher education as the autonomy coalition objected to the Ministry's proposal. The two coalitions tried to influence Parliament on the policy-defining coordination mechanisms through weak conflict. It took various plenary sessions in Parliament, informal and formal negotiations, and lobbying by both the autonomy coalition and the systemic coalition to convince Parliament of the coalitions' ideas.

On the basis of participatory observations during meetings that MESCT organized with subsystem members, it became clear that MESCT sought to create commitment and gain support from actors in the sector for its new policies through an indirect strategy. It strengthened its ties with higher education institutions, ministries, provincial representatives, the business sector, donors, members of parliament, and consultants. For example, MESCT appointed key people in the higher education sector to help develop policies and to generate debate and consult with the sector on its behalf. By having meetings, debates, workshops and seminars organized, MESCT both consulted and informed subsystem actors and managed to increase the number of members for the systemic coalition. This type of approach can be characterized as weak coordination.

Through analysis of the change in resources, this study found that MESCT used various instruments to support and realise its policy objectives. From the beginning it used financial resources to gain support from higher education actors. The Higher Education Strategic Plan (2001) to a large extent was funded through a World Bank loan, which was named the Higher Education Project 1 (HEP 1) (World Bank. 2002). Through this project, MESCT could offer public institutions substantive financial resources. Institutions 
therefore had good reasons to cooperate with MESCT. Given that MESCT managed and controlled this budget, public institutions had to comply with the guidelines set by MESCT and therefore became increasingly dependent. The implementation of HEP 1 started in mid-2002, making its full impact fall outside of our research period.

Besides funding from the HEP 1 project, higher education institutions received money from the Ministry of Finance and Planning (MPF). As had been the case prior to 2000, the rectors of the public institutions negotiated these resources directly with the MPF. However, unlike the previous period, MESCT was present during these negotiations (Boletim de República, Law no. 14/2000, 2000). The higher education institutions had to send their budget proposal to MESCT which gave its opinion during the negotiation meetings. The MPF, however, had final authority in terms of actual funding.

With respect to legal interdependency, during the first years of MESCT the institutions to a large extent were still independent from the Ministry. Basically, MESCT had to develop its new policies and regulations from scratch. This simply took time. Law no. 5/2003 on higher education was approved at the end of 2002, which meant that between 2000 and 2002 the sector operated under Law no. 1/93 (which did not mention MESCT). On the one hand, the institutions in practice could not disregard MESCT as Law no. 14/2000 broadly defined the mandate of the Ministry. But on the other hand, MESCT could not begin implementing its key policies until Law no. 05/2003 was approved.

As to the resource "information", MESCT and the other subsystem actors were symbiotically dependent on each other. MESCT developed a wide range of informal mechanisms to exchange information. Through organizing workshops, national seminars and meetings, subsystem actors (rectors, academics, representatives from MINED, people from the business sector and representatives from donor organizations) actively discussed higher education issues. People from MINED, the business sector and the provinces were interested in exchanging information. MESCT needed input from these actors to identify shortcomings and problems in order to develop viable policies. At the same time, these actors wanted to know how the Ministry could help them in realising their goals or improving certain aspects of the higher education sector.

In conclusion, from a resource perspective public higher education institutions gradually became more dependent on MESCT with the implementation of HEP 1 in mid-2002. As Law no. 05/2003 was not yet approved, legally MESCT could not start implementing policies indicated in the strategic plan. With respect to information, actors were symbiotically dependent on each other. Overall, during the period 2000-2002, actors increasingly became dependent on MESCT compared to the pre-2000 situation.

At the end of 2002, Parliament approved Law no. 05/2003 defining the new tasks and authority of the various actors (Boletim de República, Law no. 05/2003, 2003). Basically, the policy core belief of the systemic coalition had not changed. But the systemic coalition started with the implementation of the higher education sector-wide policy, affecting the majority of actors in the higher education subsystem. These actors were not only the institutions, but also the business community, because the latter participated in the National Council on Higher Education, Science and Technology (CNESCT), advising the Council of Ministers. We interpret the policy change in 2002 therefore as ranking somewhere between minor and major change.

Policy developments in 2003

Shortly after MESCT was established, the key policy issue for dispute became the proposed coordination mechanism that demarcated the new division of decision-making 
power and authority. Yet in 2003 it turned out that the key actors agreed on the same policy core beliefs. This can be interpreted as the rectors moving more in the direction of MESCT. The higher education actors agreed in 2003 that MESCT should have the coordinating role in the higher education sector and they again put forward various reasons in favour of MESCT undertaking such a role. They had experienced the positive effects of MESCT, which actively supported the interests of higher education in general and had mobilized substantive resources for the institutions. The rectors furthermore indicated that it would be more efficient if one body took care of and worked out the various initiatives than for separate institutions to develop their own strategies or infrastructure. The higher education subsystem therefore once again was characterized by one policy core namely the need for one central body coordinating and harmonising the higher education subsystem and developing guidelines and incentives.

MESCT actively continued expanding the systemic coalition during 2003. Due to its strategic actions, that is, mobilizing resources for actors to realise their goals and through extensive consultations and dialogues, MESCT was able to reach consensus and gain support for a number of major policy initiatives. An example of this was the development of the previously-contested quality assurance and credit transfer policy. In 2003 resistance towards the new MESCT had decreased and rectors joined the systemic coalition so that once again the higher education subsystem saw one coalition.

With respect to resources, the 2000-2002 resources continued in 2003, with the rectors becoming more dependent on MESCT. The implementation of HEP 1 was completed which made public universities financially more dependent on MESCT as it mobilized financial resources from the World Bank for the higher education institutions. From interviews with heads of financial departments of the public higher education institutions and from internal documents such as annual financial reports from the public universities, it can be concluded that, in 2003, the World Bank credit was one of the main sources of income for the public institutions.

With the higher education Law no. 05/2003 approved, MESCT had the mandate to define the sector's funding formula. Although the MPF still held the final decision over how much the institutions received in total, Law no. 05/2003 stipulated that the MPF was bound by the funding policy as defined by MESCT. This policy change obviously strengthened MESCT's position.

Information generation and exchange in 2003 did not differ greatly from the period 2000-2002. MESCT continued to invite new actors to contribute to the discussion on policy issues, such as the development of the quality assurance system. MESCT expanded the higher education subsystem and used the new actors as information sources.

Thus, compared with the period 2000-2002, the higher education institutions in 2003 legally and financially were more dependent on MESCT. With regards to the resource "information", the nature of the relationship between MESCT and other higher education subsystem actors remained the same as during the period 2000-2002. The systemic coalition initiated the development of new policies, specifically the introduction of a credit and accumulation transfer system and a quality assurance system, through weak coordination.

\section{Testing the hypotheses}

The following section analyzes whether the logic of the ACF stands up to empirical testing in the case of the Mozambican higher education subsystem. 
Expectation 1 In nascent subsystems that emerge out of new issues or a new conceptualization, policy beliefs are fragmented.

The Government of Mozambique shifted in the early 1990s from Marxist-Leninist principles to Liberalism. The new political ideology had consequences for higher education. Government control diminished, academic autonomy was awarded to the institutions, and rectors were able to influence higher education policy. Hence, both the status and role of actors and the market in the higher education sector was different compared to the previous political period, as were the key relationships and ensuing dynamics. Thus the status of the higher education subsystem can be classified as a nascent subsystem shaped by new issues and new conceptualizations.

In the second half of the 1990s, the rectors focused on higher education's inability to meet the demands of society as a whole. Responding to this, rectors sought to mobilize support for a national co-ordination unit to develop a sector-wide policy for higher education. Throughout the second half of the 1990s the higher education subsystem consisted of one advocacy coalition, which we labelled the systemic coalition, which held the policy core belief that stood for "higher education sector-wide policy development under the guidance of a national coordination unit". Ironically, once this coordination unit was established in the form of MESCT, the rectors themselves changed position. They left the systemic coalition between 2000 and 2002 and converged in the autonomy coalition. This coalition pressed for more power and autonomy for the rectors. A year later, however, they rejoined the systemic coalition. Rectors had reconciled themselves with the fact that Parliament had approved Law no. 05/2003. Other actors, such as MINED, government representatives of the provinces, donors, and the business community, endorsed the same policy core belief during the second half of the 1990s. They supported the introduction of higher education sector-wide policies under the guidance of a national coordination unit. MESCT itself existed only from 2000 onwards. In the three years that its position and policy beliefs were studied, it held the same policy core belief, that is, the development of sector-wide policies under its own guidance.

In sum, the empirical findings show that from 1996 actors actively attempted to influence higher education policy. Generally all actors held the same policy core belief during the period 1996 to 2003. Only the rectors changed position for a short period (20002002). The empirical reality thus goes against the ACF expectation about fragmented beliefs in nascent subsystems that emerge out of new issues or a new conceptualization. Yet care is needed in drawing conclusions from this study for three reasons. First, the empirical findings apply to a particular context which may have had an impact on the degree of fragmentation. Second, the research period covers "only" a 10-year period. Third, although the majority of the coalition members had the same policy belief during this period, the rectors did change position for a short period of time. As far the first point is concerned, the Mozambican case is unusual because the number of policy actors in the nascent higher education subsystem was small. All policy issues focused solely on higher education because all actors related to this sector. All actors had the same understanding of the specific policy issue. There was only one policy core belief in the system. Although the rectors changed position for a short period, generally everyone agreed with the need for a sector-wide higher education policy under a new national coordination unit, set apart from MINED. However, Sabatier and Jenkins-Smith assume that every subsystem contains a large number of actors. They state "whatever the origins, subsystems normally contain a large and diverse set of actors" (Sabatier and Jenkins-Smith 1993, p. 25). The ACF generally applies to complex subsystems covering a number of different sectors and policy 
issues. In many of their studies, such as the Lake Tahoe study, for instance, environment issues, economic development, water quality and urbanisation shaped the policy process (Sabatier and Brasher 1993). In the cases they studied, Sabatier and Jenkins-Smith did not envisage nascent subsystems where practically everything needs to be developed from scratch: government institutions (at different levels), higher education institutions, and a business sector. In such types of nascent subsystems, and certainly in the Mozambican case, the number of actors is small.

Policy actors, therefore, were primarily concerned with creating the basic structure for the higher education sector-policies, regulations and institutions essential for the sector to work. They were mainly involved in one core issue that clearly needed to be resolved: the division of authority between higher education institutions and the Government/MESCT. This issue dominated the higher education subsystem during its first 10 years and most of the actors' time and effort was devoted to this. Once the division of authority between actors was settled in 2003, other major policy issues arose in the higher education subsystem.

This brings us to the second reason for caution when drawing firm conclusions from this study. The duration of our period of study was relatively short. Once the higher education law no. 05/2003 was enacted, MESCT started developing new policies, for example quality assurance, credit transfer and entrance to higher education. It may well be that these proposals for policies later on become issues around which actors form new coalitions. Already with respect to the access policy, the last two years have seen questions raised as to whether for students from the north of the country different criteria for access should apply than for those from the south. Access policy thus could generate a conflict on the north-south issue, which in ACF terms relates to the core belief "whose welfare counts"? This issue could very well become a core issue around which actors from the systemic coalition, or even from other organizations or subsystems, come together. As the higher education subsystem is confronted with more policy issues, as more people enter it, additional policy cores could emerge, solidify and subsequently further fragment actors' core beliefs.

Coming back to the third point, we argue that when the majority of advocacy coalition members in a nascent subsystem retain the same policy core belief over a period of at least 10 years, then one cannot say that policy core beliefs are fragmented. Only the rectors temporarily changed their policy core beliefs for a short period of time. In order to speak of fragmented beliefs, we would expect a larger variety of beliefs and more changes in beliefs over the research period.

Expectation 2 The type of interaction between actors is dependent on the interaction between the nature of the policy beliefs that actors hold and the nature of the interdependency of actors.

Table 2 summarizes the nature of policy beliefs, interdependency and the outcomes of the type of interaction between actors in the higher education subsystem during the three phases 1993-1999, 2000-2002, and 2003. To ascertain whether the empirical findings correspond to the expectations, row three and row four are compared.

The outcomes during the years 1993-1999 (congruent beliefs and independence result in weak coordination) and during 2000-2002 (divergent beliefs and independence result in weak conflict) are in line with the expectation formulated. It should be added that these outcomes could also have been explained by Zafonte and Sabatier (1998). However, in 2003 when the rectors depended on MESCT for resources, a case of competitive interdependency emerged which Zafonte and Sabatier do not refer to. If their expectations were 
Table 2 Summary of the nature of actors' beliefs, interdependency, and interaction, 1993-2003

\begin{tabular}{|c|c|c|}
\hline 1993-1999 & $2000-2002$ & 2003 \\
\hline Policy core belief: Congruent & Policy core belief: Divergent & Policy core belief: Congruent \\
\hline $\begin{array}{l}\text { Nature of dependency: } \\
\text { independent }\end{array}$ & $\begin{array}{l}\text { Nature of dependency: Relatively } \\
\text { independent (financially more } \\
\text { dependent than in previous years, } \\
\text { legally still independent) }\end{array}$ & $\begin{array}{l}\text { Nature of dependency: } \\
\text { Dependent }\end{array}$ \\
\hline $\begin{array}{l}\text { Common action: Weak } \\
\text { coordination }\end{array}$ & Common action: Weak conflict & $\begin{array}{l}\text { Common action: Weak } \\
\text { coordination }\end{array}$ \\
\hline $\begin{array}{l}\text { Expected common action: } \\
\text { Weak coordination }\end{array}$ & $\begin{array}{l}\text { Expected common action: Weak } \\
\text { conflict }\end{array}$ & $\begin{array}{l}\text { Expected common action: } \\
\text { Coalition with severe } \\
\text { collective action problems }\end{array}$ \\
\hline
\end{tabular}

applied to the situation in 2003, Zafonte and Sabatier would argue that the actors were dependent on each other, and given that their beliefs were congruent, they would anticipate strong coordination. Their expectation concerning coalition behavior therefore would not match the empirical findings. Fenger and Klok, on the other hand, do distinguish between the types of dependency, yet their expectations are not corroborated by the empirical findings (either). However, they are-in our view-closer to the empirical findings than Zafonte and Sabatier. According to Fenger and Klok, before coalitions fall apart their preceding common action corresponds either to weak coordination or to strong coordination. When actors hold congruent beliefs but compete for resources, Fenger and Klok entertain the possibility of both weak coordination and strong coordination (which at a later stage dissolves). Although it should be admitted that their prediction (weak or stronger coordination) is rather safe, their expectations are nevertheless in line with the empirical findings.

The expectations are confirmed for most of the period of investigation. Although the expectations of Fenger and Klok do not (fully) match the empirical findings, rejecting their predictions again requires caution. One year of investigation is too short a period in which to reach firm conclusions. After 2004, for example, actors may have noticed that their substantial investment in time and energy paid-off only in weak coordination. Which then could have resulted in a weakening and dissolution of the coalition. Yet, for that to happen, the actors must have previously engaged in weak or strong coordination, which indeed is what occurred in 2003.

Expectation 3a Major policy change happens infrequently, that is only after a decade or more.

Expectation $3 \mathrm{~b}$ If major policy change occurs, it is due to changes external to the subsystem.

In the early 1990s, the government abandoned the strict socialist doctrine it had previously held and embraced a new liberal constitution. For higher education, this implied adopting a new law: Law no. 1/93. In ACF terms, this major policy change was caused by changes in (stable) factors outside the subsystem.

No major policy change took place during the following seven years. With the establishment of MESCT in 2000 a second major policy change took place. This change is considered major because it relates to the "(re)distribution of authority" (Sabatier and Jenkins-Smith 1999, p. 133). It was driven by forces external to the subsystem. In ACF 
terms it was due to changes in the dynamic factors, that is, a change in government. Two years later, in 2002, a further shift in policy took place, closely related to the major policy change in 2000. The systemic coalition, which was dominant at that time, gave further meaning to the higher education sector-wide policy and developed new coordination mechanisms by means of the new higher education law. The policy goal coincided with the policy core topic "distribution of authority". The policy change of 2002 was an ambiguous case whereby secondary aspects coincided with policy core belief topics and had an impact on the whole subsystem. The latter policy change, as demonstrated before, was caused by the interaction between the two coalitions and not by external factors outside the higher education subsystem.

Thus, in the period 1993-2003, three specific policy changes took place. Those of 1993 and 2000 qualify as major policy change. The policy of 2002 was ambiguous with regard to qualifying as either major or minor policy change. The first major change in 1993 was driven by changes in fundamental norms about social and political constructs. The second change (2000) was instigated by external factors, namely as a consequence of elections. The reform of 2002 was the product of interaction between actors in the higher education subsystem. The assertion that major change happens infrequently is not confirmed by the empirical findings. Major policy change took place more frequently than the ACF predicted. However, major policy change did take place in response to changes external to the subsystem (for the period 1993-2000). The policy change in 2002, which we found difficult to qualify as either major or minor change, resulted from interaction within the subsystem.

The study on Mozambique proves to be a case that includes characteristics which in industrialized countries are seldom present. However, expectations about the infrequency of major policy change cannot be rejected solely on the basis of this study. The first policy change was a consequence of changes in the political construct, which Sabatier and Jenkins-Smith assume occurs seldom, hence the ACF does not further specify the implications for the variables included in the model. What is important, is to take into account the lack of political and other institutional features in nascent subsystems in developing countries. Mozambican actors with decision-making power were few and the number of embedded regulations and institutions was limited. Many commentators (for example Grin and Hoppe 1997; John 2003; Kübler 2001) point out that institutions, such as intermediate organizations, voting systems, the division of powers, and the salience of the higher courts, can be crucial features that impact on policy processes and change. In the Mozambican higher education subsystem the dominant systemic coalition promoted and advanced policy change, and it experienced little resistance due to the non-existence of other actors and institutions that could block or slow down change.

\section{Conclusions}

This article studied the dynamics of a nascent subsystem in a turbulent country. It showed that the dynamics of policy processes and change can be different in countries in which fundamental structural elements (basic laws and regulations on decision-making power, new institutions to implement and control the law) have yet to be developed and established. The Mozambican case shows that subsystems can also emerge after radical changes in the political constellation. Sabatier and Jenkins-Smith refer to these changes as changes in the "stable factors outside the subsystem". According to them these changes rarely take place and, so far, no study has concentrated on the policy implications for subsystems that 
emerged under these conditions. Arguably, the notion of new subsystem emergence merits further refinement.

This research also reminds us that we have to be very careful in drawing firm conclusions. First, the period when we studied higher education in Mozambique was relatively short. Second, our findings are based on a single case study. However, on the basis of this study it can be concluded that the ACF is built on basic assumptions that do not necessarily apply to countries with a high degree of civil and political turbulence. For example, Sabatier and Jenkins-Smith posit that, no matter what conditions a nascent subsystem emerges from, the subsystem involves a large number of actors. They assume that subsystems consist of more than one policy core. Actors will always have enduring conflicting perceptions about policy issues and topics. Sabatier and Jenkins-Smith assume further that environmental factors outside the subsystem are relatively stable and consequently major policy change is infrequent. This study shows that these assumptions need to be questioned. They may not hold for cases of policy formation and change in developing countries. Moreover, one can question the uniformity of nascent systems. Does an average uniform period exist during which subsystems are nascent? This period may well be dependent on the context in which the subsystem develops; in Mozambique, for example, the higher education subsystem could still be termed "nascent" after 10 years. It is difficult to predict when such a system is mature. It may take another 10 years and it could well be that actors' core beliefs become fragmented later on in this development period. Additionally, one can question whether the dynamic external factors as defined by Sabatier and Jenkins-Smith are the only type of factors that change actors' policy core beliefs in nascent subsystems. Perhaps a lesser degree of external shock may be enough for a change in the policy core beliefs. Moreover, the lack of understanding of the meaning and implications of the new policies may also be a factor that influences the extent to which policy beliefs are stable or fragmented.

Before definitive conclusions can be drawn on those aspects of the ACF studied here, more research is needed on cases where nascent subsystems emerge in turbulent environments. In particular, it would be interesting to apply the ACF to subsystems in conditions similar to the Mozambican ones. The research conducted here, however, suggests that the ACF needs to be refined. The forms of interaction between actors should be scrutinized, and attention should be paid to the role of institutions (their absence or sparseness) in policy change. Finally, the issue of how the characteristics of such subsystems influence the frequency of major policy change merits closer attention.

Open Access This article is distributed under the terms of the Creative Commons Attribution Noncommercial License which permits any noncommercial use, distribution, and reproduction in any medium, provided the original author(s) and source are credited.

\section{References}

Anderson, C. J. M. (1999). Change and continuity in Poland's environmental policy. Dordrecht: Kluwer Academic Publishers.

Boletim de República, Law 1/93. (1993). Regula a actividade do ensino superior na República de Moçambique. Maputo: Government of Mozambique.

Boletim de República, Law 14/2000. (2000). Define as atribuiçoes e competências do Ministério de Ensino Superior Ciência e Tecnologia. Maputo: Government of Mozambique.

Boletim de República, Law 05/2003. (2003). Maputo: Government of Mozambique.

Brito, L. (2003). The Mozambican experience; initiating and sustaining tertiary education reform. Paper presented at the Regional Training Conference on Improving Tertiary Education in Sub-Saharan Africa: Things that Work! Accra, Sep 2003. 
Eberg, J. W. (1997). Waste policy and learning: Policy dynamics of waste management and waste incineration in the Netherlands and Bavaria. Delft: Eburon.

Elliot, C. (1999). Forest certification in Indonesia, Canada and Sweden. Lausanne: Swiss Institute of Technology.

Fenger, M., \& Klok, P. J. (2001). Interdependency, beliefs, and coalition behaviour: A contribution to the advocacy coalition framework. Policy Sciences, 34(2), 157-170. doi:10.1023/A:1010330511419.

Grin, J., \& Hoppe, R.(1997). Towards a theory of the policy process: Problems, promises and prospects of the ACF. Paper presented at the Sabatier Workshop (Polybios, ARIPS meeting), Amsterdam.

John, P. (2003). Is there life after policy streams, advocacy coalitions, and punctuations: Using evolutionary theory to explain policy change? Policy Studies, 31(4), 481-498. doi:10.1111/1541-0072.00039.

Kübler, D. (2001). Understanding policy change with the advocacy coalition framework: An application to Swiss drug policy. Journal of European Public Policy, 8(4), 623-641. doi:10.1080/135017601100 64429.

Mário, M., Fry, P., Levey, L., \& Chilundo, A. (2003). Higher education in Mozambique. Oxford: James Curry.

Ministério de Ensino Superior Ciência e Tecnologia (MESCT). (2000). Strategic plan of higher education in Mozambique 2000-2010. Mozambique: Maputo.

Parsons, W. (1995). Public policy: An introduction to the theory and practice of policy analysis. Cheltenham, UK: Edward Elgar.

Sabatier, P. A. (1988). An advocacy coalition framework for policy change and the role of policy learning therein. Policy Sciences, 21, 129-168. doi:10.1007/BF00136406.

Sabatier, P. A., \& Brasher, A. (1993). From vague consensus to clearly differentiated coalitions: Environmental policy at Lake Tahoe, 1964-1985. In P. A. Sabatier \& H. C. Jenkins-Smith (Eds.), Policy change and learning: An advocacy coalition approach (pp. 177-235). Boulder: Westview Press.

Sabatier, P. A., \& Jenkins-Smith, H. C. (1993). The advocacy framework: Assessment, revisions, and implications for scholars and practitioners. In P. A. Sabatier \& H. C. Jenkins-Smith (Eds.), Policy change and learning: An advocacy coalition approach (pp. 211-235). Boulder: Westview Press.

Sabatier, P. A., \& Jenkins-Smith, H. C. (1999). The advocacy coalition framework: An assessment. In P. A. Sabatier (Ed.), Theories of the policy process: Theoretical lenses on public policy (pp. 117-166). Boulder: Westview Press.

Sabatier, P. A., \& Weible, C. M. (2007). The advocacy coalition framework. Innovations and Clarifications. In P. A. Sabatier (Ed.), Theories of the policy process (pp. 189-200). Boulder: Westview Press.

Schlager, E., \& Blomquist, W. (1996). A comparison of three emerging theories of the policy process. Political Research Quarterly, 49(3), 651-672.

World Bank. (2002). Project appraisal document for a higher education project (No. 22962-MOZ). Washington DC: World Bank.

Zafonte, M., \& Sabatier, P. (1998). Delineating policy networks-shared beliefs and imposed interdependencies as determinants of ally networks in overlapping subsystems. Journal of Theoretical Politics, 10(4), 473-506. doi:10.1177/0951692898010004005. 